\title{
Multiple large and small cerebellar infarcts
}

\author{
Sandrine Canaple, Julien Bogousslavsky
}

\begin{abstract}
To assess the clinical, topographical, and aetiological features of multiple cerebellar infarcts, 18 patients $(16.5 \%$ of patients with cerebellar infarction) were collected from a prospective acute stroke registry, using a standard investigation protocol including MRI and magnetic resonance angiography. Infarcts in the posterior inferior cerebellar artery (PICA)+superior cerebellar artery (SCA) territory were most common (9/18; $50 \%$ ), followed by PICA+anterior inferior cerebellar artery (AICA)+SCA territory infarcts $(6 / 18 ; 33 \%)$. One patient had bilateral AICA infarcts. No infarct involved the PICA+AICA combined territory. Other infarcts in the posterior circulation were present in half of the patients and the clinical presentation largely depended on them. Large artery disease was the main aetiology. Our findings emphasised the common occurrence of very small multiple cerebellar infarcts ( $<2 \mathrm{~cm}$ diameter). These very small multiple cerebellar infarcts may occur with (13 patients/18; $72 \%$ ) or without $(3 / 18 ; 22 \%)$ territorial cerebellar infarcts. Unlike previous series, they could not all be considered junctional infarcts (between two main cerebellar artery territories: 51/91), but also small territorial infarcts (40/91). It is suggested that these very small territorial infarcts may be endzone infarcts, due to the involvement of small distal arterial branches. It is possible that some very small territorial infarcts may be due to a microembolic process, but this hypothesis needs pathological confirmation. (f Neurol Neurosurg Psychiatry 1999;66:739-745)
\end{abstract}

Keywords: magnetic resonance imaging; cerebellar infarction; epidemiology

Service de Neurologie, Centre Hospitalier Universitaire Vaudois, Lausanne, Switzerland S Canaple

J Bogousslavsky

Correspondence to:

Dr Julien Bogousslavsky,

Service de Neurologie,

Centre Hospitalier

Universitaire Vaudois,

CH-1011, Lausanne,

Switzerland. Telephone 0041

2131412 20; fax 004121

3141231 ; email

Julien.Bogousslavsky@

chuv.hospvd.ch

Received 30 January 1998

and in final form

8 December 1998

Accepted 11 December 1998
The patterns of multiple cerebellar infarcts have been poorly studied. Historically, they had the reputation of a bad prognosis because the first studies were necropsy series. ${ }^{1}$ Since the advent of CT and more recently MRI, very precise clinical and radiological correlation could be established in the infarcts involving the territory of the main cerebellar arteries, also allowing the recognition of benign and asymptomatic forms. In the New England Medical Center posterior circulation registry (NEMC), over $40 \%$ of patients with cerebellar infarction also had infarcts in other territories. ${ }^{2}$ New types of cerebellar infarcts have also been emphasised (watershed infarcts, very small infarcts). ${ }^{3-5}$ However, the association of several cerebellar infarcts in individual patients has not been specifically studied. The aim of our work was to study the clinical, topographical, aetiological, and pathophysiological patterns of multiple cerebellar infarcts.

\section{Patients and methods}

We studied 18 consecutive patients with $>1$ cerebellar infarct, who were included consecutively in the Lausanne Stroke Registry. ${ }^{6}$ All the patients had systematic investigations (brain CT, Doppler ultrasonography with B mode echotomography of the carotid and vertebral arteries, ECG, three lead ECG monitoring for at least 24 hours after admission, standard blood tests). ${ }^{6}$ Brain MRI was performed in all patients with presumed involvement of the posterior circulation, following a standard protocol using a Siemens Magnetom 63 SP (Siemens AG Erlanger, Germany) 1.5 T. Brain MRI consisted of conventional sagittal and transverse T1 and T2 weighted images with 5 $\mathrm{mm}$ thick slices, and for 15 patients flow sequence (magnetic resonance angiography (MRA)) centred on the posterior fossa, including the vertebral, basilar, and the posterior cerebral arteries. Four vessel catheter angiography was performed in two patients. Transthoracic two dimensional echocardiography was performed in 12 patients and transesophageal echocardiography in three patients after specific selection criteria ( $<50$ years; suspected cardioembolic source). ${ }^{7}$

The topography of the cerebellar infarcts was determined according to the maps establishing anatomical correspondence with dominant arterial territories proposed by Tatu et $a l,{ }^{8}$ in agreement with previous studies. ${ }^{19-13}$

The topographic classification of the infarcts was as follows:

- territorial infarcts occupying the territory of the posterior inferior cerebellar artery (PICA), medial branch of the PICA (m PICA), lateral branch of the PICA (1 PICA); the territory of the superior cerebellar artery (SCA), medial branch of SCA (m SCA), lateral branch of SCA (1 SCA); the territory of the anterior inferior cerebellar artery (AICA). Lesions in the brainstem were also assessed as follows:

- infarcts located at the boundary region between two main arterial territories, which we called junctional infarcts (because the term watershed infarct implies a haemodynamic mechanism)

- multiple cerebellar infarcts-that is, separate infarcts involving at least two cerebellar artery territories (PICA, AICA, SCA, unilateral or bilateral) on gadolinium enhanced MRI. Separate infarcts were diagnosed when non-involved parenchyma were visible on MRI between the infarcts. Large infarcts encompassing several adjacent territories were excluded. 
Infarcts $<2 \mathrm{~cm}$ in diameter were called very small. ${ }^{34}$ Infarcts in other territories were also evaluated.

Risk factors included hypertension (blood pressure $>160 / 90 \mathrm{~mm} \mathrm{Hg}$ at least twice before the stroke), hypercholesterolaemia (cholesterol concentration $>5.2 \mathrm{mmol} / \mathrm{l}$ ), known diabetes mellitus, and regular cigarette smoking. History of cardiac or vascular disease was also recorded. Vertebrobasilar atherosclerosis with artery to artery embolism was presumed in patients with risk factors and stenosing atheroma in the appropriate large artery as shown by catheter angiography, MRA, or Doppler ultrasonography. Cardiac embolism was suspected in patients with potential sources of embolism, such as atrial fibrillation, dilated cardiomyopathy, mitral stenosis, or prosthetic heart valve, left ventricular akinesia after myocardial infarction, and in rarer cardiac diseases. ${ }^{14}{ }^{15}$ Other causes of stroke were recorded, including hypercoagulable state, vertebral artery dissection, arteritis, and rarer diseases.

\section{Results}

There were 13 men and five women (mean age 63 years, range 34 and 81 years). They corresponded to $16.5 \%$ of patients with cerebellar infarct included in the Lausanne Stroke Registry (table 1). ${ }^{6}$
VASCULAR CONCOMITANTS

Six patients had hypertension, five smoked cigarettes regularly, three had diabetes mellitus, three had hypercholesterolaemia. Five patients had at least two cumulative risk factors, whereas seven had none of them. Two patients had a history of previous myocardial infarction and two had angina pectoris. Previous transient ischaemic attacks (TIAs) were noted in five patients, suggesting involvement of the posterior circulation in two of them (following the clinical criteria of Trouillas et $\left.a l^{16}\right)$. One patient with an anterior circulation TIA, had a carotid artery stenosis, and two patients had TIAs in an undefined territory.

TOPOGRAPHY OF CEREBELLAR INFARCTS

Sixteen patients had infarction in the PICA territory, 11 unilateral and four bilateral. In one patient involvement of the medullary territory of the m PICA was demonstrated on MRI. Thirty eight defined foci of infarcts were seen in the PICA territory, seven involving the full territory of the PICA, two only the m PICA, 19 junctional between the $\mathrm{m}$ and 1 PICA territory), and 10 very small in the $m$ and 1 PICA territory.

Eight patients had infarction in the territory of the AICA, five unilateral and three bilateral. The pontine territory of the AICA was involved in five patients, four of them had just brachium

Table 1 General features of the patients

\begin{tabular}{|c|c|c|c|c|c|}
\hline $\begin{array}{l}\text { Patient } \\
\text { No/Age/Sex }\end{array}$ & Risk factors & Symptoms and signs & Other infarcts & Cause & Outcome \\
\hline $1 / 69 / \mathrm{M}$ & $\begin{array}{l}\text { HTA } \\
\text { HChol }\end{array}$ & $\begin{array}{l}\text { Tinnitus+hearing loss; } \mathrm{M}(\mathrm{f}, \mathrm{u}, \mathrm{l}) \mathrm{R} ; \mathrm{S}(\mathrm{f}, \mathrm{u}, \mathrm{l}) \mathrm{R} \\
\mathrm{OD} \text {; dysarthria+GA }\end{array}$ & No & Atherothrombotic & Favourable M1 \\
\hline $2 / 78 / \mathrm{F}$ & No & $\mathrm{M}(\mathrm{f}, \mathrm{u}, \mathrm{l}) \mathrm{R} ; \mathrm{HH} ; \mathrm{Npsy}$ & $\begin{array}{l}\text { Thalamus, L } \\
\text { occipital, L }\end{array}$ & Unknown & Persistent Npsy M1 \\
\hline $3 / 81 / \mathrm{F}$ & HTA & $\begin{array}{l}\text { Headaches }+V+\text { nausea } \\
\text { mild } M(f, u, l) L ; O D ; \text { dysarthria }\end{array}$ & $\begin{array}{l}\text { cerebral peduncle, } \\
\mathrm{R}\end{array}$ & Atherothrombotic & Favourable M1 \\
\hline $4 / 78 / \mathrm{M}$ & DID & $\begin{array}{l}\text { Headaches+nausea; HH; Npsy; OD; } \\
\text { GA, LA, L }\end{array}$ & $\begin{array}{l}\text { Lacunes+ } \\
\text { occipital, R }\end{array}$ & Atherothrombotic & $\begin{array}{l}\text { Favourable M1 } \\
\text { persistent mild GA }\end{array}$ \\
\hline $5 / 46 / M$ & $\begin{array}{l}\text { Tobacco } \\
\text { HChol }\end{array}$ & $\begin{array}{l}\text { Headaches+nausea+vomiting+V+tinnitus, } \\
\text { mild M(u) R; OD; GA+LA, R }\end{array}$ & No & Atherothrombotic & $\begin{array}{l}\text { Favourable } \\
\text { M1 }\end{array}$ \\
\hline 6/75/M & $\begin{array}{l}\text { HTA } \\
\text { DNID }\end{array}$ & $\begin{array}{l}\text { M(f) L; Npsy, } \\
\text { GA+bilat LA+dysarthria }\end{array}$ & Lacunes & Atherothrombotic & Dependent M1 \\
\hline $7 / 41 / \mathrm{F}$ & Tobacco & Headaches+cervicalgia; Transient $\mathrm{M}(\mathrm{u}, 1) \mathrm{L} ; \mathrm{HH}$ & Occipital, R & Dissection? & Favourable J3 \\
\hline $8 / 50 / \mathrm{M}$ & No & Headaches+nausea; $M(u, 1)$ bilat; Npsy; dysarthria & Thalamus, L & $\begin{array}{l}\text { Cardioemb(ASA) } \\
\text { +essential thrombocythemia }\end{array}$ & Favourable J 7 \\
\hline 9/36/M & No & Tinnitus+hearing loss; OD; GA+LA, R +dysarthria & No & $\begin{array}{l}\text { ASA+PFO+antiphospholipid } \\
\text { syndrome }\end{array}$ & $\begin{array}{l}\text { J13 haemorrhagic } \\
\text { transformation } \Rightarrow \\
\text { ventricular derivation } \\
\text { Independent M4 }\end{array}$ \\
\hline $10 / 34 / \mathrm{F}$ & No & $\begin{array}{l}\text { Nausea+vomiting+V; mild M (u)R; S (f)R } \\
\text { SD; Npsy; GA+bilat LA }\end{array}$ & $\begin{array}{l}\text { Rostral } \\
\text { mesencephalic } \\
\text { tegmentum }\end{array}$ & $\begin{array}{l}\text { Cardioembolic } \\
\text { (PFO) }\end{array}$ & Favourable M2 \\
\hline $11 / 76 / \mathrm{M}$ & No & $\mathrm{V}+$ nausea+vomiting; OD; GA, bilat LA & No & $\begin{array}{l}\text { Cardioembolic } \\
\text { (ASA+PFO) }\end{array}$ & Favourable M1 \\
\hline $12 / 61 / \mathrm{M}$ & HTA HChol & $M$ bilat $f+M(u, 1) R ; S$ bilat $f+(u, 1) R ; S D$ & $\begin{array}{l}\text { Anterior sylvian } \\
\text { infarct, bilat+lacunes }\end{array}$ & $\begin{array}{l}\text { Cardioembolic } \\
\text { (ventric.akinesia, } \\
\text { L)+atherothrombotic. }\end{array}$ & Dependent M1 \\
\hline \multirow[t]{2}{*}{$13 / 71 / \mathrm{M}$} & HTA & V+vomiting; mild $M(\mathrm{u}, \mathrm{l}) \mathrm{L} ; \mathrm{S}(\mathrm{f}, \mathrm{u}, \mathrm{l}) \mathrm{L}$, & thalamic, $\mathrm{R}+$ & Atherothrombotic & $\begin{array}{l}\text { J8 persistant cerebellar } \\
\text { dysfunction }\end{array}$ \\
\hline & $\begin{array}{l}\text { HChol } \\
\text { Tobacco }\end{array}$ & $\begin{array}{l}\text { Npsy; HH; OD } \\
\text { GA+ LA, L+dysarthria }\end{array}$ & Temporo-occipital, L & & \\
\hline $14 / 46 / \mathrm{F}$ & Tobacco & $\begin{array}{l}\text { V+headaches; tinnitus; } M(f, u, 1) R \text {; transient } \mathrm{HH} \\
\text { LA, R+dysarthria }\end{array}$ & $\begin{array}{l}\text { Semi ovale centre } \\
\text { (lacune) }\end{array}$ & $\begin{array}{l}\text { Cardioembolic } \\
\text { (PFO) }\end{array}$ & Favourable J10 \\
\hline $15 / 81 / M$ & No & $\begin{array}{l}\text { Decreased alertness; fluctuating bilat } M(\mathrm{u}, 1) \text {; } \\
\text { Npsy; } \\
\text { bilat LA }\end{array}$ & $\begin{array}{l}\text { Thalamic, bilat+ } \\
\text { occipital, bilat }\end{array}$ & $\begin{array}{l}\text { Horton's disease+ } \\
\text { Polycythemia }\end{array}$ & Dependent M1 \\
\hline $16 / 63 / \mathrm{M}$ & Tobacco & $\begin{array}{l}\text { Headaches+V; OD, hearing loss; } M(f, u) R \\
\text { S (u, l)R; OD; LA, R+dysarthria }\end{array}$ & Occipital, R & Unknown & J14 favourable \\
\hline $17 / 75 / \mathrm{M}$ & No & $\begin{array}{l}\text { Headaches+V+vomiting+hearing loss } \\
\text { M(f, l)R; OD, SD; GA+ bilat LA+dysarthria }\end{array}$ & No & Unknown & $\begin{array}{l}\text { J2: coma, hydrocep } \\
\Rightarrow \text { craniotomia } \\
\mathrm{J} 15 \text { favourable }\end{array}$ \\
\hline $18 / 72 / \mathrm{M}$ & HTA & S(l)R; GA + bilat LA & No & Horton's disease & J14 favourable \\
\hline
\end{tabular}

$\mathrm{M}=$ motor weakness; $\mathrm{S}=$ sensory disturbances; $\mathrm{HH}=$ homonymous hemianopia; $\mathrm{L}=\mathrm{Left}$ side; $\mathrm{R}=$ Right side; $\mathrm{f}=$ face; $\mathrm{u}=\mathrm{upper}$ limb; $\mathrm{l}=\mathrm{lower}$ limb; $\mathrm{Npsy}=$ neuropsychological disturbances; $\mathrm{V}=$ vertigo; $\mathrm{GA}=$ gait ataxia; $\mathrm{LA}=\mathrm{limb}$ ataxia, $\mathrm{OD}=$ oculomotor disturbances; $\mathrm{SD}=\mathrm{swallowing}$ disturbances 

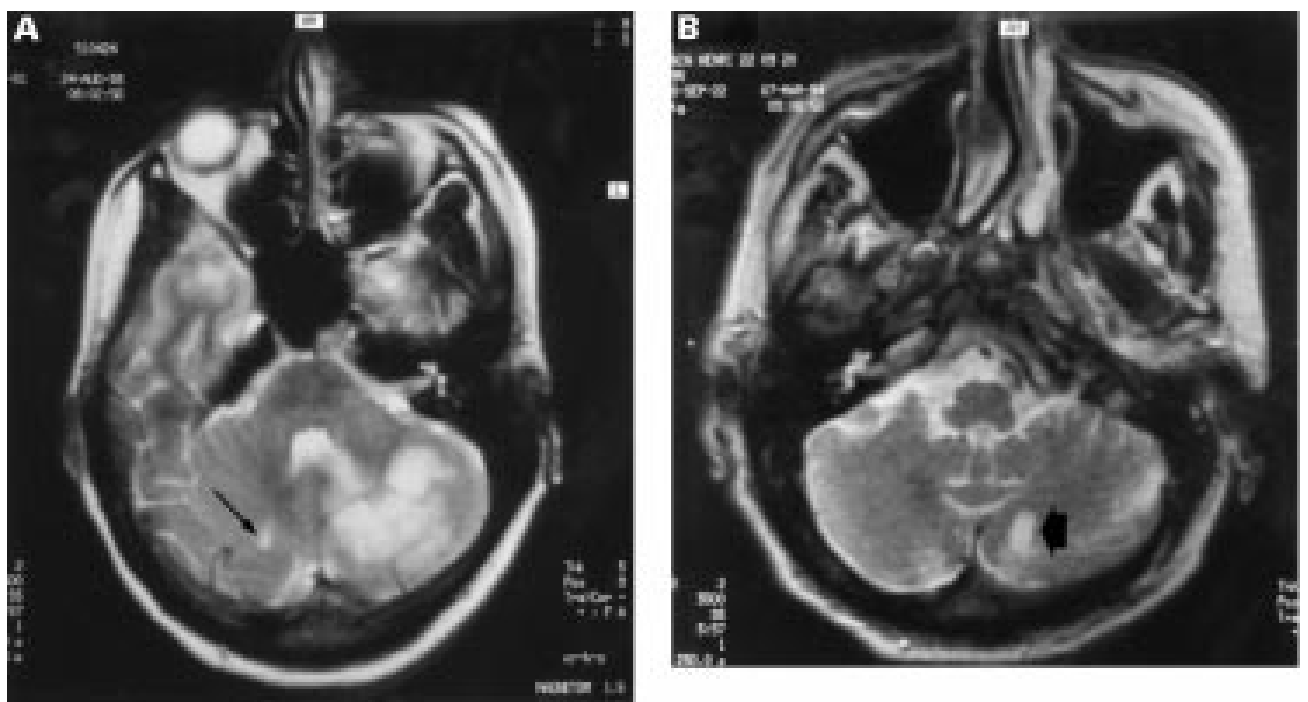

Figure 1 (A) patient 10 with cardioembolic cause. T2 weighted MRI axial section: right very small territorial infarct in the $m S C A$ territory (arrow) +large infarcts in the left SCA and the $m$ PICA territories. (B) patient 13 with atherothrombotic cause: very small infarct in the territory of the left MPICA (arrowhead).

pontis involvement. Only three AICA infarcts were very small.

Seventeen patients had infarcts in the SCA territory, four unilateral and 14 bilateral. Sixty eight defined foci of infarcts were seen in the SCA territory, five involving the full territory of the SCA, none the territory of the m SCA, seven the territory of the 1 SCA, 29 junctional between the $\mathrm{m}$ and $1 \mathrm{SCA}$, (all but one very small in size), and 27 very small non-junctional (territorial), located in the 1 SCA, less often the m SCA territory. In two patients the involvement of the pontine territory of the SCA was seen on MRI.

In nine patients, infarcts were in the combined territory of PICA and SCA, in two patients in the combined territory of AICA and SCA, in six patients in the combined territory of PICA, AICA, and SCA, in one patient in the AICA territory on both sides.

Very small infarcts $(<2 \mathrm{~cm})$ were numerous $(n=91)$ in our patients. In a first step, we tried to classify them into the five groups proposed by Amarenco et $a l^{\beta}$ :

(1) 13 patients had group I infarcts - cortical infarcts - at the boundary zones between SCA and PICA (medial/lateral branches of the PICA, medial branch of PICA/SCA, and medial/lateral branches of the SCA).

(2) Nine patients had group II infarctsinfarcts involving the deep white matter of the cerebellum (one or several infarcts for each patient)-located at the deep boundary zones between AICA, 1 and $\mathrm{m} \mathrm{SCA}$, and 1 and $\mathrm{m}$ PICA.

(3) Two patients had group III infarctsinfarcts involving the medial rostral cerebellum between the right and the left SCA.

(4) One patient had one group IV infarctcortical superficial infarct.

(5) One patient had group $\mathrm{V}$ infarctsinfarcts at the boundary zone between PICA and AICA.

We often found an association between group I and group II infarcts (9/18 patients). Overall 16 of our 18 patients had one or several very small infarcts, and 12 had associated large territorial and very small infarcts.

However, many very small infarcts (40 lesions) could not be included in this classification because they were not boundary in location. We called them very small, territorial (fig 1). Ten patients had such infarcts, often associated with group I and group II infarcts (fig 2).

OTHER INFARCTS AND LESIONS

Nine patients had infarcts involving other territories in the posterior circulation (midbrain, thalamus, temporal, or occipital lobes).

One patient had two old infarcts in the anterior circulation.

Four patients had white matter lesions in the cerebral hemispheres, either with scarce areas of focal hyperintense signal (four patients) or in a multifocal diffuse pattern (one patient).

\section{ARTERIAL LESIONS}

Arterial investigations (MRA, Doppler ultrasounds, catheter arteriography) were normal in five patients, showed basilar stenosis in four patients, vertebral artery lesions in nine patients, occlusion or irregularities of the calibre of cerebellar arteries in two patients, and occlusion of the posterior cerebral artery (PCA) in one patient. Among the vertebral artery lesions, there were two bilateral occlusions, two bilateral stenoses, two cases of unilateral occlusion with contralateral stenosis, one unilateral vertebral artery origin (VAO) stenosis, two bilateral VAO stenoses.

Eight patients also had carotid atherosclerosis, including six patients with non-stenosing plaques, one patient with a bilateral $<50 \%$ stenosis, and one patient with known carotid occlusion.

CAUSES OF STROKE

Six patients had vertebrobasilar atherosclerotic disease as the only cause of stroke. Paradoxical embolism was possible in three patients with patent foramen ovale in two, or atrial septal aneurysm with patent foramen ovale (in one). 


\begin{tabular}{|c|c|c|c|c|}
\hline $\begin{array}{l}\text { Patient } \\
\text { No }\end{array}$ & Large territorial & $\begin{array}{l}\text { Non-territorial } \\
\text { (junctional) } \\
<2 \mathrm{~cm}\end{array}$ & $\begin{array}{l}\text { Small, } \\
\text { territorial } \\
<2 \mathrm{~cm}\end{array}$ & Topography of the multiple large and small cerebellar infarcts \\
\hline 1 & AICA, bilat & & & \\
\hline 2 & $\begin{array}{l}\text { Full PICA, uni } \\
\text { AICA, uni } \\
\text { I SCA, uni }\end{array}$ & GII & Yes & \\
\hline 3 & & GI, GII & Yes & \\
\hline 4 & $\begin{array}{l}\text { Full PICA, uni } \\
\text { AICA, uni } \\
\text { I SCA, uni }\end{array}$ & $\mathrm{Gl}$ & & \\
\hline 5 & $\begin{array}{l}\text { m PICA, uni } \\
\text { I SCA, L }\end{array}$ & GI, GII, GIII & & \\
\hline 6 & AICA, bilat & GI, GII & Yes & \\
\hline 7 & & GIII & Yes & \\
\hline 8 & & GI, GII, GIV & Yes & \\
\hline 9 & $\begin{array}{l}\text { AICA, bilat } \\
\text { Full SCA, bilat }\end{array}$ & GI, GII, GV & & \\
\hline
\end{tabular}

Figure $2 A$ General and topographic distribution of cerebellar infarcts. GI-GV=group I-group V infarcts; $R=$ right; $L=$ left.

In four patients, there were two coexisting possible aetiologies: atrial septal aneurysm+patent foramen ovale+antiphospholipid syndrome, old myocardial infarction with septal akinesia+ large vessel atheroslerotic disease with slow basilar artery blood flow, atrial septal aneurysm +essential thrombocythemia, giant cell arteritis+polycythemia. Two patients had other causes: giant cell arteritis and vertebral dissection. In three patients, the cause remained unknown.

For aetiological correlation, we subdivided infarcts into two groups: large territorial infarcts and very small infarcts. In fact, in $13 / 18$ cases, these infarcts coexisted.

In large territorial infarcts and in combined large territorial and very small infarcts, we failed to show a specific correlation between the topographic pattern of involvement and the underlying cause of stroke.

Three patients had exclusively multiple small infarcts in different territories. Patient 3 had multiple group I and group II infarcts in the territory of the PICA and the SCA, and bilateral subclavian artery stenosis. $\mathrm{He}$ also had very small territorial infarcts. He had several TIAs in the weeks before the stroke. Patient 7 was a young woman who had a TIA with transient hemianopia and hemiparesis 3 hours after traumatic hyperextension of the cervical spine, which resulted in vertebral artery dissection. Brain MRI showed very small territorial and junctional (group III) infarcts. Patient 8 with possible paradoxical embolism (patent foramen ovale+atrial septal aneurism) had multiple group I and group II infarcts in the 


\begin{tabular}{|c|c|c|c|c|}
\hline $\begin{array}{l}\text { Patient } \\
\text { No }\end{array}$ & Large territorial & $\begin{array}{l}\text { Non-territorial } \\
\text { (junctional) } \\
<2 \mathrm{~cm}\end{array}$ & $\begin{array}{l}\text { Small, } \\
\text { territorial } \\
<2 \mathrm{~cm}\end{array}$ & Topography of the multiple large and small cerebellar infarcts \\
\hline 10 & $\begin{array}{l}\text { m PICA, uni } \\
\text { Full SCA, uni }\end{array}$ & & Yes & \\
\hline 11 & Full PICA, uni & GI, GII & Yes & \\
\hline 12 & AICA, uni & GI, GII & Yes & \\
\hline 13 & I SCA, uni & & Yes & \\
\hline 14 & $\begin{array}{l}\text { AICA, uni } \\
\text { I SCA, uni }\end{array}$ & GI, GII & & \\
\hline 15 & $\begin{array}{l}\text { Full PICA, bilat } \\
\text { Full SCA, bilat }\end{array}$ & & & \\
\hline 16 & I SCA & $\mathrm{Gl}$ & Yes & \\
\hline 17 & $\begin{array}{l}\text { Full PICA, uni } \\
\text { I SCA, uni }\end{array}$ & GI & & \\
\hline 18 & Full PICA, uni & GI, GII & Yes & \\
\hline
\end{tabular}

Figure $2 B \quad G I=$ group I infarcts; $G I I=$ group II; GIII=group III; GIV=group IV; $G V=$ group $V ; R=$ right; $L=$ left; uni=unilateral; bilat $=$ bilateral.

territory of PICA and SCA. He had also a group IV and very small territorial infarcts.

CLINICAL FEATURES

The main clinical features appear in table 2, with, in order of decreasing frequency, motor weakness, limb ataxia, gait ataxia, dysarthria, vertigo, nausea and vomiting, and headache.

A pseudotumorous evolution was seen in one patient with an infarct in the right PICA and I SCA territory, with two group I infarcts in the SCA territory. A severe decrease in consciousness was found 48 hours after the first symptoms, and the development of hydrocephalus on repeated CT made a ventriculostomy necessary. The outcome was favourable. Another patient needed a ventricular shunt after haemorrhagic transformation under anticoagulation on the 13th day after the stroke, the evolution being also favourable. One patient had a top of the basilar syndrome. ${ }^{17}$ Three patients of the 15 patients with an infarct in the PICA territory had clinical signs of

Table 2 Main clinical features of the patients

\begin{tabular}{lc}
\hline Main clinical features & No of patients \\
\hline Vertigo & 8 \\
Nausea, vomiting & 8 \\
Headaches & 8 \\
Dysarthria & 9 \\
Hearing loss, tinnitus & 6 \\
Decreased alertness & 1 \\
Diplopia & 5 \\
Gait ataxia & 10 \\
Limb ataxia & 12 \\
Nystagmus & 6 \\
Motor weakness (f \pm u \pm 1$)$ & \\
$\quad$ unilateral or bilateral & 14 \\
\hline
\end{tabular}

$\mathrm{f}=$ face; $\mathrm{u}=$ upper limb; l=lower limb. 
lateral medullary involvement, but MRI showed the corresponding lesion in a single patient. Infarcts in the AICA territory were associated with clinical signs of involvement of the lateral pons in half of the patients. In SCA territory infarcts, the involvement of the upper pontine tectum was present in only two patients. Dysarthria was found in nine patients. None of the patients died during the first month.

\section{Discussion}

The most frequent type of multiple cerebellar infarcts involved the PICA+SCA territory, followed by PICA+AICA+SCA territory infarcts. Multiple infarcts were not limited to the cerebellum, as other infarcts in the posterior circulation were present in half of the patients. Infarcts in the SCA territory are often accompanied by other infarcts in the territory of branches of the rostral basilar artery. ${ }^{10} 18$ However, in our series, SCA territory and distal infarcts in the posterior circulation involving thalamus or occipital lobe, were also often associated with PICA territory infarcts (proximal-distal infarcts in the posterior circulation).

We found a high proportion of very small infarcts, with or without associated large territorial infarcts. Indeed, less than $10 \%$ of the patients had no very small infarct. The description of these very small cerebellar infarcts is recent ${ }^{13-5}$ and previous series focused on large territorial infarcts. ${ }^{219}{ }^{20}$ In our study, many of the very small infarcts were not junctional, which differs notably from what was emphasised in previous series, ${ }^{134}$ where very small infarcts were mainly reported to be located at the boundary zones of the territories of the PICA, AICA, SCA, or their branches. ${ }^{3}$ However, about half of them could be considered junctional only when enlarging the border zones in the deep white matter of the cerebellum. ${ }^{21}$ In fact, this area is mostly supplied by the SCA, although it has been previously considered a border zone between the penetrating branches of the PICA, SCA, and AICA. ${ }^{21}$ Infarcts in this area were initially reported to be rare ${ }^{21}$ but in our series they were common, mostly in the territory of the PICA, where they cannot be confounded with junctional infarcts. To our knowledge, this last category of cerebellar infarcts has not been adequately delineated in the literature. A new category is needed to classify them, and we propose that they are called very small territorial infarcts. These very small infarcts may be endzone infarcts, territorial infarcts due to the involvement of small distal arteries. The existence of such infarcts has been suspected ${ }^{4}$ but with a junctional (non-territorial) classification, which is misleading in terms of arterial territories.

The clinical presentation seemed to depend for the most part on the associated infarcts, which signs overshadowed cerebellar dysfunction. Surprisingly, in patients often with a large part of the cerebellar parenchyma being infarcted, pseudotumorous forms were rare. The most frequent symptoms (vertigo, nausea, vomiting, headaches, dysarthria, abnormal gait) were not different from what was found in the main series of cerebellar infarcts. ${ }^{25}$ Motor weakness (affecting facetupper limb \pm lower limb, unilateral, or bilateral) was the most common deficit. We think that in the setting of cerebellar infarction, this may allow one to suspect multiple infarcts. Indeed, limb and gait ataxia is the most common deficit in single cerebellar infarction. ${ }^{25}$ We had one patient (7) with very small multiple bilateral infarcts with no cerebellar sign at all on clinical examination. This has been reported with territorial infarcts, especially in the 1 PICA,${ }^{22}$ but also $\mathrm{m} \mathrm{PICA},{ }^{23} 1$ SCA,${ }^{24}$ and $\mathrm{m}$ SCA territory. ${ }^{25}$ Neurological examination can even be normal in some cases of small nonterritorial infarcts. ${ }^{4}$ The strikingly good evolution of our patients may be explained by the fact that the most severe cases died before admission to hospital or were in too severe a condition to have MRI, so probably the selected patients were not the most severe cases, or that there was no case of severe lesion of the brainstem, but also that we systematically collected the cases of very small infarcts.

As in a previous report from our group in $1993,{ }^{15}$ which emphasised the importance of intracranial large artery disease in the posterior circulation, we found that in situ atherothrombotic mechanism was a common cause of multiple cerebellar infarcts. Although artery to artery embolism could have explained multiple cerebellar infarcts in several of our patients, we also presumed a haemodynamic mechanism in some cases, as suggested by signs of decreased flow in the basilar artery on MRA or Doppler ultrasounds ${ }^{26}$ Embolism from the heart was unlikely in most patients, as only three patients, including one with coexisting large artery disease, had a potential cardioembolic aetiology. Also, the low proportion of patent foramen ovale found in our population did not suggest that paradoxical emboli was a major mechanism of multiple cerebellar infarcts. Given the low number of patients in each subgroup, no clear relation could be established between the pattern of involvement in the posterior circulation (proximal $v$ middle $v$ distal ${ }^{18}$ ), the size of the lesion (large $v$ very small infarcts), and the presumed aetiology of stroke. The group of three patients with multiple bilateral very small infarcts without associated large cerebellar territorial infarct is particularly interesting. The possibility of lacunar stroke due to small artery disease, although never reported in the cerebellum with pathological correlation, ${ }^{14}$ may be considered, at least for patient 3, aged 81, with hypertension, who had group II very small deep infarcts. However, a haemodynamic factor is also likely in this patient, as he had bilateral subclavian stenosis and symptoms associated with postural hypotension. The two remaining patients $(7,8)$ possibly had embolic sources. All three patients had very small territorial and junctional infarcts, which may suggest that most very small infarcts may be embolic, or that the vascular supply in the cerebellum may widely differ from patient to patient, so that apparently territorial infarcts may in fact be considered junctional, or vice versa. Large territorial and 
very small non-territorial infarcts have the same vascular risk factors, clinical presentation, causes, and mechanisms in a large recent series. ${ }^{4}$ We showed the existence of a new subgroup of very small territorial infarcts, using a new anatomical map. ${ }^{8}$ We think that further studies should consider this category. Indeed, if the characteristics of very small territorial and very small non-territorial infarcts are the same, it may be artificial to separate territorial and junctional cerebellar infarcts.

In conclusion, our findings show that (1) multiple cerebellar infarcts are often very small, with or without larger territorial infarcts, (2) pseudotumorous effects are unusual despite the large amount of cerebellar tissue involved, (3) many patients do not have prominent cerebellar signs, and a few have just transient benign symptoms, (4) over half the patients have multiple cerebellar infarcts without other posterior circulation parenchymatous infarction, (5) many of the very small infarcts do not fit into the previous classifications of cerebellar infarcts and we describe a new subgroup of very small territorial infarcts, (6) very small cerebellar infarcts are a non-specific finding with multiple possible mechanims, the commonest is an in situ atherothrombotic mechanism. We suggest that further studies should consider a new group of very small territorial cerebellar infarcts.

We thank Thomas Heinsius and Alain Barth for their help in collecting the patients' data.

1 Amarenco P. The spectrum of cerebellar infarctions. Neurology 1991;41:973-9.

2 Caplan L. Cerebellar infarcts; posterior circulation disease. Oxford: Blackwell Scientific Publication, 1995:492-543.

3 Amarenco P, Kase CS, Rosengart A, et al. Very small (border zone) cerebellar infarcts. Distribution, causes, mechader zone) cerebellar infarcts. Distribution, causes,
nisms and clinical features. Brain 1993;116;161-86.

4 Amarenco P, Lévy C, Cohen A, et al. Causes and Amarenco P, Levy C, Cohen A, et al. Causes and mechanisms of territorial and nonterritorial cerebellar inf-

5 Barth A, Bogousslavsky J, Regli F. The clinical and Barth A, Bogousslavsky J, Regli F. The clinical and
topographic spectrum of cerebellar infarcts; a clinicaltopographic spectrum of cerebellar infarcts; a clinicalmagnetic resonanc
6 Bogousslavsky J, Van Melle G, Regli F.The Lausanne Stroke Registry; analysis of 1000 consecutive patients with first Registry; analysis of 1000 cons
stroke. Stroke 1988;19;1083-92.

7 Bogousslavsky J, Cachin C, Regli F, et al. Cardiac sources of embolism and cerebral infarction; clinical consequences and vascular concomitants: the Lausanne Stroke Registry. Neurology 1991;41:855-9.

8 Tatu L, Moulin T, Bogousslavsky J, et al. Arterial territories of human brain; brainstem and cerebellum. Neurology 1996;47:1125-35.

9 Amarenco P, Hauw J-J. Anatomie des artères cérébelleuses. Rev Neurol 1989;145:267-76

10 Amarenco P, Hauw J-J. Cerebellar infarction in the territory of the superior cerebellar artery; a clinicopathologic study of 33 cases. Neurology 1990;40:1383-90.

11 Duvernoy HM. Human brainstem vessels. Berlin: Springer -Verlag, 1978.

12 Duvernoy HM. The human brainstem and cerebellum. Surface, structure, vascularization and three dimensional Surface, structure, vascularization and three dimensional

13 Marinkovic S, Kovacevic M, Gibo H, et al. The anatomical Marinkovic S, Kovacevic M, Gibo H, et al. The anatomical
basis for the cerebellar infarcts. Surg Neurol 1995;44:45061

4 Amarenco P, Caplan LR. Vertebrobasilar occlusive disease; review of selected aspects. 3. Mechanisms of cerebellar infarctions. Cerebrovasc Dis 1993;3:66-73.

15 Bogousslavsky J, Regli F, Maeder P, et al. The etiology of posterior circulation infarcts; a prospective study using posterior circulation infarcts; a prospective study using angiography. Neurology 1993;43:1528-33.

16 Trouillas P, Nighoghossian N, Philippon B. Nuclear hemodynamic vertebrobasilar insufficiency. A new approach with the Xe 133 method. Arch Neurol 1991;48:921-9

17 Caplan LR. Top of the basilar syndrome. Neurology 1980;30:72-9.

18 Caplan LR, Amarenco P, Rosengart A, et al. Embolism from vertebral artery origin occlusive disease. Neurology 1992; 42:1505-12.

19 Kase C, Norrving B, Levine S, et al. Cerebellar infarction. Clinical and anatomic observations in 66 cases. Stroke 1993;24;76-83.

20 Tohgi H, Takahashi S, Chibra K, et al. Cerebellar infarction. Clinical and neuroimaging analysis in 293 patients. Stroke 1993;24;1697-701.

21 Savoiardo M, Bracchi M, Passerini A, et al. The vascular territories in the cerebellum and brainstem: CT and MR study. AfNR Am ₹ Neuroradiol 1987;8:199-209.

22 Barth A, Bogousslavsky J, Regli F. Infarcts in the territory of the lateral branch of the posterior inferior cerebellar artery. 7 Neurol Neurosurg Psychiatry 1994;57:1073-6.

23 Amarenco P, Roullet E, Hommel M, et al. Infarction in the territory of the medial branch of the posterior inferior cerebellar artery. F Neurol Neurosurg Psychiatry 1990;53: $731-5$.

24 Bogousslavsky J, Regli F. Lateropulsion axiale isolée lors d'un infarctus cérébelleux flocculonodulaire. Rev Neurol 1984;140:140-4.

25 Kase C, White J, Joslyn J, et al. Cerebellar infarction in the superior cerebellar artery distribution. Neurology 1985;35: $705-11$.

26 Röther J, Wentz K-U, Rautenberg W, et al. Magnetic resonance angiography in vertebrobasilar ischemia. Stroke 1993;24:1310-15. 